\title{
Determinants of Whistleblowing Intention in Organization
}

\author{
Azizan Mohamed-Isa ${ }^{1 *}$, Ahmed Razman Abdul Latiff ${ }^{2}$, Mohammad Noor Hisham Osman ${ }^{3}$, \\ Arman Hj Ahmad ${ }^{4}$
}

\author{
${ }^{1}$ Department of Management \& Entrepreneurship, Universiti Kuala Lumpur Business School \\ ${ }^{2}$ Putra Business School, Serdang, Malaysia \\ ${ }^{3}$ Faculty of Economics and Management, Universiti Putra Malaysia \\ ${ }^{4}$ Department of Marketing \& International Business, Universiti Kuala Lumpur Business School
}

Received: $25 / 07 / 2020$

Accepted: 03/10/2020

Published: $10 / 10 / 2020$

\begin{abstract}
Whistleblowers have been applauded for their heroic acts for disclosing unethical practices in organization worldwide such as Enron, Worldcom and Cambridge Analytica to name a few. Whistleblowing has been regarded as one of the internal control mechanisms to prevent organizational wrongdoings. Despite establishment and enhancement of law, policies and regulations enacted to whistleblowing, potential whistleblowers remain silent and reluctant to blow the whistle. It is therefore important to examine the factors that encourage individual to come forward to disclose the wrongdoing. This conceptual article reviews prior literature that examined determinants of whist leblowing intentions. Building from the theory and following the prior literature, the article expanded the review by looking into the interaction of determinants such as ethical leadership, emotional intelligence and whistleblowing intention. Hence, it is expected that study of such interaction would create new avenues for future research.
\end{abstract}

Keywords: Whistleblowing intention, ethical leadership, emotional intelligence, organizational misconduct

\section{Introduction}

Whistleblowing is a disclosure of unethical practices of individuals or a group of individuals via designated avenues in the organization (1). Whistleblowing is regarded as valuable tool for curbing and detecting misconduct in organizations. Due to its importance role, major world organizations such as Organization for Economic Cooperation and Development (OECD) and European Commission are calling for implementation of whistleblowing policy and procedure. The downfall of US based companies such as Enron and Worldcom due to accounting scandals came to light as a result of whistleblowing (2). Based on survey assessed by the Association of Fraud Examiners has found that $40 \%$ of occupational fraud detected by whistleblowers (3).

A whistleblower who reports the wrongdoing believed that any misconduct happened in the organizations should be conveyed to authorities or management for corrective measures. Many countries have prepared laws to facilitate and encourage more whistleblowers to step forward in reporting unethical practices occured in their organizations. Among countries which have been recognised to have a very comprehensive whistleblowing legislations coverage in public and private sector are USA (Corporate and Auditing Accountability, Responsibility and Transparency Act 2002, commonly known as SarbanesOxley Act), Japan (Whistleblower Protection Act 2004), Korea
(Protection of Public Interest Whistleblowers 2011) and Republic of South Africa (Protected Disclosures Act, 2000, Companies Act, 2008) (4). Meanwhile in England, English Parliament enacted the Public Interest Disclosure Act 1998 (PIDA 1998) as a provision for whistleblowing in the country. In Malaysia, the regulations regarding reporting of wrongdoing (misconduct) can be found in Malaysian Anti-Corruption Commission Act 2009, Capital Market and Service Act 2007, Company Act (as Amended) 2007 (1, 5).

Nonetheless, despite the establishment of the whistleblowing regulatory framework and policies across countries, whistleblowing is not a common business practice (6). Employees whom witness misconduct in organization prefer not to come forward to disclose the wrongdoing and remain silent due to risky and ambiguity elements associated with the whistleblowing behaviour. Previous studies on whistleblowing has shown that among the factors why employees reluctant to report the misconduct is fear of retaliations, believe such effort will be futile, lead to negative appraisals, job loss, career jeopardy, and to the extent that an ongoing persecution (6-8).

Given the aspect of whistleblowing as an important mechanism in exposing wrongdoing and misconduct in organization, it is vital for management to understand the factors that determine the likelihood of employees to whistleblow. Putting systems and regulations in place may not guarantee the

Corresponding author: Azizan Mohamed-Isa, Department of Management \& Entrepreneurship, Universiti Kuala Lumpur Business School. E-mail: azizan@unikl.edu.my 
employees to report misconduct, due to risk and uncertainties associated with the respective disclosure. For whistleblowing to happen effectively, key influential factors that may increase the likelihood of employees to report wrongdoing may derived from organizational and individual perspectives. Previous study posits that whistleblowing policy will only be effective if the leaders provide an environment, which encourages and reinforces the ethical behaviour (9).

This article aims to explore the impact of ethical leaders in the employees' organizational environment to increase the likelihood of whistleblowing (whistleblowing intention). In addition, whistleblowing may also depends on the individual aspect of employees. It is not an easy decision for employees to resort with whistleblowing (10). There are many states of emotion involve that lingers in the mind of employees when seeing misconduct happen. The feeling such as anger, disbelief, upset in acknowledging the incidences. However, before the employee decide to disclose the misconduct, the feeling of fear, distress and anxious will exist knowing the negative consequences will take place soon after reporting. Employees with high level of emotional intelligence tend to exhibit more adaptive defence mechanism such as denial (11) and may have the ability to regulate own emotion effectively when encounter the risk, overcome fears, and thus will increase the likelihood of whistleblowing.

This article is structured in three parts. First, the article deliberates the literature based on two factors of whistleblowing that are organizational and individual. Second, from the respective findings, a conceptual framework of whistleblowing intentions is proposed. The final part of the article culminates the significance of whistleblowing intentions in the organizations.

\section{Literature review}

The topic of whistleblowing has gained substantial interest from numerous researchers nearly forty years ago. Many researches have since been conducted in an attempt to provide framework for whistleblowing intention. The proposed framework illustrated the determinants which either influence and/or facilitate whistleblowing intention. Understanding these contributing factors would be able to provide insightful guidelines that may increase the likelihood for employees to whistleblow. This article explore the impact of ethical leaders and the personal attributes of employees on whistleblowing intention.

\subsection{Whistleblowing and whistleblowing intention}

Chiu (12), states that whistleblowing can be defined as "the voluntary release of information, as a moral protest by a member of an organization about illegal or immoral conduct in the organization that is opposed to the public interest". MacNab and Worthley (13) state that "whistleblowing as a communication process in which the process itself focuses on voluntary reporting of potential or improper acts by an employee or ex-employee within an organisation to authorities". There are two types of whistleblowing; internal and external. The act of disclosing unethical conduct happened in organizations or its members can be done internally or externally (14).

Internal whistleblowing happens when a whistleblower reports the act of misconduct to someone of authority within an organization or through a confidential hotline $(13,15)$. External whistleblowing arises when a whistleblower discloses the illegal practices in the organization and decides to bring the matters to the attention of external parties, such as law enforcement agencies, political representatives, external advocacy groups, non-governmental organizations, mass media or journalists (1618). Prior studies have shown that both internal and external channels have been employed to report wrongdoings. According to Miceli and Near $(15,19)$, almost all whistlebowers made an effort to disclose misconduct by way of internal channels prior to using external channels.

\subsection{Whistleblowing intention}

It is rather difficult to measure the actual whistleblowing by first hand observation due to infeasibility and complexity in performing investigations of misconducts in the work setting. It is preferable to study actual cases of whistleblowing actions and behaviours, nonetheless scholars examining whistleblowing are often limited to examining reporting intention due to its occasional characteristics $(7,20-22)$. Whistleblowing is a sensitive topic, thus it poses challenge in gaining entry into organizations and participants may fear their anonymity might be compromised (23). As such, previous studies used whistleblowing intention as a proxy for actual whistleblowing behaviour $(24,25)$. Therefore, this article considers whistleblowing intention as the main subject of the study and addresses both internal and external channels of reporting.

\subsection{Ethical leadership and whistleblowing intention}

Ethical leadership plays such a central role in encouraging employees to report organizational wrongdoings. Corporate misconduct may be detected through whistleblowing and organizations and leaders may be able to encourage the whistleblowing action (26). Previous research illustrates drawing from social learning theory and social learning perspective of leadership, posit that leaders may affect ethical attitudes and behaviour by way of role modelling (27). Ethical leaders as moral managers will enhance the employees' ethical consciousness and encourage their whistleblowing intention in several ways.

First, leader is observed as an ethical role model by the employees. They are regarded as credible, trustworthy, responsible and speak up against inappropriate misconduct occur in organization. Employees observe those behaviours and influence them thus modelling the normatively appropriate behaviour. Employees are expected to report any observed unethical conduct and ethical leaders support this reporting behaviour.

Second, given the fact that the negative consequences associated with whistleblowing such as retaliation, employees probably are ready to accept those risk with the presence of ethical leaders. Ethical leaders may protect them against risk of retaliation and any risk associated with whistleblowing. Whistleblowers are regarded as helpful to organization and they should be given appreciation, support and rewards.

Third ethical leaders are seen to establish standards, creating the appropriate norms and practices and hold direct reports accountable (28). They set expectation and support the reporting behaviour. Thus, it is proposed that:

Proposition 1: Ethical Leadership positively influences whistleblowing intention

\subsection{Emotional intelligence and business ethics setting}

Previous research has substantially investigated the role of 
emotion in business ethics setting (29-33). Emotional intelligence, represent an importance personal attributes related to ethical decision making in whistleblowing. Only very recently, researchers started to investigate the effects of emotional intelligence on business ethics.

Emotional intelligence (EI) is defined as the skills to observe one's own and others feelings, to distinguish among them and to utilize the information as a guidance on one's thinking and action (34, p.189). The definition was later honed and categorized based upon four dimension: identifying, facilitating, understanding, and regulating emotions.

The concept of emotional intelligence has been used widely in the management research due to its practicality aspect in work environment such as performance, job satisfaction, absenteeism, organizational commitment, intentions, and leadership issues (35). Emotional intelligence is an ability acquired by people whereby the set of of skills that can be taught, learned, and/or acquired. The intelligence skills may be developed through role models from organization and appropriate training (36).

\subsection{Moderating role of emotional intelligence}

Emotional intelligence (EI) has been proposed to act as moderator for the relationships between ethical leadership and whistleblowing intention in this study. Much of the current literature pays particular attention to the direct influences of antecedents on whistleblowing and neglecting the possible moderating factors on these influences (37).

EI is anticipated to moderate the relationship between ethical leadership and whistleblowing intention. Individual with EI may have a more positive expectation when disclose unethical practices and shows less concern about probable risks, and potentially involved in risk-taking events (38). Hence, individual with high level of EI hve the inclination that there is minimal risk involved in whistleblowing, and avoid harsh retaliation.

High emotional intelligence individuals are more conscious of their own and others' feelings (39). They have the ability to understand emotional information, pay attention to the relationships among them, and accurately managing feelings (40). Emotionally intelligent employees are able to address their supervisors unstated needs (41). They can easily strengthen the emotional connections with their supervisors thus intensify the ethical leadership impact (42). An employee would anticipate a lot of emotional responses before deciding to become potential whistleblower. Individuals whom possess high level of emotional intelligence are optimistic and remain focused on the outcome positive rather than negative ones.

This article proposed that the relationship between ethical leadership and whistleblowing intention will be moderated by emotional intelligence (EI), such that the relationship will be stronger for people with high EI than people with low EI.

Proposition 2: The relationship between ethical leadership and whistleblowing intention is moderated by emotional intelligence in a way that ethical leadership positively impacts whistleblowing intention when the employees exhibit high degree of emotional intelligence.

\section{Methodology}

This study employs descriptive approach because the purpose of this study is to describe the nature of relationships that exist among ethical leadership, emotional intelligence and whistleblowing intention. This study applies quantitative approach with the adoption of Structural Equation Modelling using Smart PLS as the quantitative analytical tool. Survey method is adopted and this study utilizes self-administered questionnaires that match appropriately to measure the constructs. The research entailed using systematic random sampling techniques by collecting data obtained from Malaysian AntiCorruption Commission (MACC) website.

\subsection{Proposed conceptual framework}

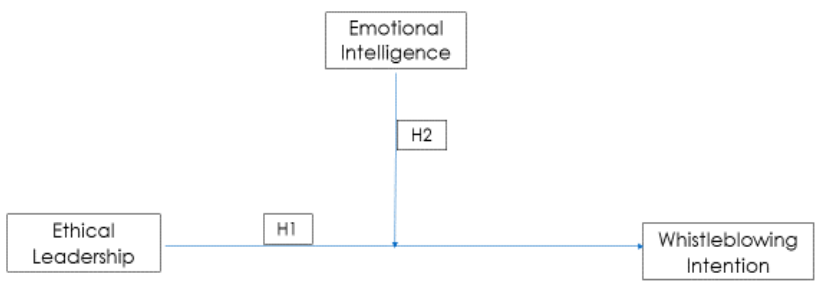

Figure 1. Conceptual framework for determinants of whistleblowing intention in organizations

\subsection{Instruments and measurement}

The items of the variables in the questionnaire were adapted from previous studies related with whistleblowing intention, ethical leadership, and emotional intelligence to go well with the research objectives of the study. Respondents will be requested to respond to the statement of the question using a six-point Likert scale ranging from 1 "strongly disagree" to 6 "strongly agree", to record the degree of their assessment and perception on each item.

The scale of "Whistleblowing Intention" will be adapted from Park and Blenkinsopp's (43) 8-item scale. The first part measured whistleblowing intention and Whistleblowing intention was measured through a total of 8 items, asking the question "If you found wrongdoing in your workplace, how hard would you try to do the following?" A 6-point Likert-type scale was employed to rate statements that ranged from one (1) =Not at all to six (6) = Very hard.

"Ethical Leadership" will be assessed utilizing scale developed by Brown et al. (27). Ten items of measurement reflecting individual perceptions of their leader's ethical conduct. Examples of items include '(The leader in my organisation) disciplines employees who violate ethical standards' and '(The leader in my organisation) sets an example of how to do things the right way in terms of ethics'. The reported internal consistency for this 10-item scale is 0.92 (27). Participants will respond along a 6-point Likert-type scale with anchors from 1 (strongly disagree) to 6 (strongly agree).

"Emotional Intelligence" measurement scale consist of 16 items instruments of four-dimensional classification of overall emotional intelligence proposed by Davies et al. (44). The construct of this measurement will be adopted from Law et al. (45) labeled as the Wong and Law EI Scale (WLEIS). The respondents is requested to indicate their level of agreement with each of the items on a 6-point agree-disagree scale. The higher score reflects higher level of emotional intelligence. 


\section{Conclusion}

The function of whistleblowing is crucial in exposing wrongdoing due to the nature of corruption that it is not easily detect through formal channels especially in developing countries. Employees whom witness misconduct in organization prefer not to come forward to disclose the wrongdoing and remain silent due to risky and ambiguity elements associated with the whistleblowing behaviour. In this instances, management should address the issue immediately by encouraging the employees to disclose any wrongdoing observed. Two factors are proposed as the key determinants of whistleblowing intention. These two factors are ethical leaders and emotional intelligence that might play an important roles in influencing employees' whistleblowing intention.

\section{Acknowledgment}

This study was funded through the Short Term Research Grant provided by the Centre of Research and Innovation, Universiti Kuala Lumpur.

\section{Ethical issue}

Authors are aware of, and comply with best practice in publication ethics specifically with regard to authorship (avoidance of guest authorship), dual submission, and manipulation of figures, competing interests and compliance with policies on research ethics. Authors adhere to publication requirements that submitted work is original and has not been published elsewhere in any language.

\section{Competing interests}

The authors declare that there is no conflict of interest that would prejudice the impartiality of this scientific work.

\section{Authors' contribution}

All authors contributed equally to this work

\section{References}

1. Rachagan S, Kuppusamy K. Encouraging whistle blowing to improve corporate governance? A Malaysian initiative. J Bus Ethics. 2013;115(2):367-382.

2. Bedi A, Alpaslan CM, Green S. A meta-analytic review of ethical leadership outcomes and moderators. J Bus Ethics. 2015;139(3):517536.

3. Association of Certified Fraud Examiners (ACFE). Report to the Nation's 2018 global study on occupational fraud and abuse [Internet]. 2018. Available from: https://www.acfe.com/report-tothe-nations/2018/default.aspx

4. Wolfe S, Worth M, Dreyfus S, Brown AJ. Whistleblower protection laws in G20 countries: Priorities [Internet]. 2014. Available from: https://blueprintforfreespeech.net/wpcontent/uploads/2014/09/Whist leblower-Protection-Laws-in-G20-Countries-Priorities-forAction.pdf

5. Meng TP, Fook OS. Comparative analysis of whistleblower protection legislations in England, USA and Malaysia. Afr J Bus Manage. 2011;5(27):11246-11255

6. Zhang J, Chiu R, Wei LQ. On whistleblowing judgment and intention: The roles of positive mood and organizational ethical culture. J Manage Psychol. 2009;24(7):627-649.

7. Mesmer-Magnus JR, Viswesvaran C. Whistleblowing in organizations: An examination of correlates of whistleblowing intentions, actions, and retaliation. J Bus Ethics. 2005;62(3):277-297.
8. Greene AD, Latting JK. Whistle-blowing as a form of advocacy: Guidelines for the practitioner and organization. Soc Work. 2004;49(2):219-230.

9. Lewis D. Whistleblowing in a changing legal climate: Is it time to revisit our approach to trust and loyalty at the workplace? Bus EthicsEuropean Rev. 2011;20(1):71-87.

10. Cho YJ, Song HJ. Determinants of whistleblowing within government agencies. Public Pers Manage. 2015;44(4):450-472.

11. Mayer JD, Salovey P, Caruso DR. Emotional intelligence: Theory, findings, and implications". Psychol Inq. 2004;15(3):197-215.

12. Chiu RK. Ethical judgment and whistleblowing intention: Examining the moderating role of locus of control. J Bus Ethics. 2003;43(1 2):65-74.

13. MacNab BR, Worthley R. Self-efficacy as an intrapersonal predictor for internal whistleblowing: A US and Canada examination. J Bus Ethics. 2008;79(4):407-421.

14. Miceli MP, Near JP. Characteristics of organizational climate and perceived wrongdoing associated with whistle-blowing decisions. Pers Psychol. 1985;38(3):525-544.

15. Miceli MP, Near JP. What makes whistle-blowers effective? Three field studies. Hum Relat. 2002;55(4):455-479.

16. Hollings J. Let the story go: The role of emotion in the decisionmaking process of the reluctant, vulnerable witness or whistleblower. J Bus Ethics. 2013;114(3):501-512.

17. Kaptein M. From inaction to external whistle blowing: the influence of the ethical culture of organizations on employee responses to observed wrongdoing. J Bus Ethics. 2011;98(3):513-530.

18. Ali KK, Ramly Z, Chai TC. Business ethics. 2nd ed. Oxford; 2018.

19. Miceli MP, Near JP. Blowing the whistle: The organizational and legal implications for companies and employees. Lexington Books; 1992.

20. Victor B, Trevino LK, Shapiro DL. Peer reporting of unethical behavior: The influence of justice evaluations and social context factors. J Bus Ethics. 1993;12(4):253-263.

21. Patel C. Some cross-cultural evidence on whistle-blowing as an internal control mechanism. J Int Account Res. 2003;2(1):69-96.

22. Trongmateerut $P$, Sweeney JT. The influence of subjective norms on whistle-blowing: A cross-cultural investigation. J Bus Ethics. 2013;112(3):437-451.

23. Bjørkelo B, Bye HH. On the appropriateness of research design: Intended and actual whistleblowing. In International Handbook on Whistleblowing Research. Edward Elgar Publishing; 2014.

24. Kaplan SE, Schultz JJ. Intentions to report questionable acts: An examination of the influence of anonymous reporting channel, internal audit quality, and setting. J Bus Ethics. 2007;71(2):109-124.

25. Latan H, Ringle CM, Jabbour CJC. Whistleblowing intentions among public accountants in Indonesia: Testing for the moderation effects. J Bus Ethics. 2018;152(2):573-588.

26. Dozier JB, Miceli MP. Potential predictors of whistle blowing: A proposal behavior perspective. Acad Manage Rev. 1985;10:823-836.

27. Brown ME, Treviño LK, Harrison DA. Ethical leadership: A social learning perspective for construct development and testing. Organ Behav Hum Dec. 2005;97(2):117-134.

28. Mayer DM, Nurmohamed S, Treviño LK, Shapiro DL, Schminke M. Encouraging employees to report unethical conduct internally: It takes a village. Organ Behav Hum Dec. 2013;21(1):89-103.

29. Bonifield C, Cole C. Affective responses to service failure: Anger, regret, and retaliatory versus conciliatory responses. Market Lett. 2007;18(1-2):85-99.

30. Chebat JC, Slusarczyk W. How emotions mediate the effects of perceived justice on loyalty in service recovery situations: An empirical study. J Bus Res. 2005;58(5):664-673.

31. DeWitt T, Nguyen DT, Marshall R. Exploring customer loyalty following service recovery: The mediating effects of trust and emotions. J Serv Res. 2008;10(3):269-281.

32. Schoefer K, Diamantopoulos A. The role of emotions in translating perceptions of (in) justice into post complaint behavioural responses. J Serv Res. 2008;11(1):91-103. 
33. Baron S, Harris K, Elliott D, Schoefer K, Ennew C. The impact of perceived justice on consumers' emotional responses to service complaint experiences. J Serv Mark. 2005;19(5):261-270.

34. Salovey P, Mayer JD. Emotional intelligence. Imagin Cogn Pers. 1990;9(3):185-211.

35. Rozell EJ, Pettijohn CE, Parker RS. Customer-oriented selling: Exploring the roles of emotional intelligence and organizational commitment. Psychol Market. 2004;21(6):405-424.

36. Akers MD, Porter GL. Your EQ skills: Got what it takes? J Accountancy. 2003;195(3):65-69.

37. Miceli M, Near J, Dworkin T. Whistle-blowing in organizations. Lea's Organization and Management Series, Routledge, Taylor \& Francis Group; 2008.

38. Bless H, Clore GL, Schwarz N, Golisano V, Rabe C, Wölk M. Mood and the use of scripts: Does happy mood really lead to mindlessness? J Pers Soc Psychol. 1996;71:665-679.

39. Farh CI, Seo MG, Tesluk PE. Emotional intelligence, teamwork effectiveness, and job performance: The moderating role of job context. J Appl Psychol. 2012;97(4):890-900.

40. Newman DA, Joseph DL, MacCann C. Emotional intelligence and job performance: The importance of emotion regulation and emotional labor context. Ind Organ Psychol. 2010;3(2):159-164.

41. Wolff SB, Pescosolido AT, Druskat VU. Emotional intelligence as the basis of leadership emergence in self-managing teams. Leadership Quart. 2002;13(5):505-522.

42. Qian J, Wang B, Han Z, Song B. Ethical leadership, leader-member exchange and feedback seeking: A double-moderated mediation model of emotional intelligence and work-unit structure. Front Psychol. 2017;8:1174.

43. Park H, Blenkinsopp J. Whistleblowing as planned behaviour: A survey of South Korean police officers. J Bus Ethics. 2009;85(4):545-556.

44. Davies M, Stankov L, Roberts RD. Emotional intelligence: In search of an elusive construct. J Pers Soc Psychol. 1998;75(4):989-1015.

45. Law KS, Wong CS, Song LJ. The construct and criterion validity of emotional intelligence and its potential utility for management studies. J Appl Psychol. 2004;89(3):483-496. 